\title{
Reflection of Teacher Cognition in EFL Vocabulary Instructional Practices in Indonesia
}

\author{
Istanti Hermagustiana ${ }^{1}$, Arifuddin Hamra ${ }^{2}$, Andi Qashas Rahman ${ }^{2} \&$ Kisman Salija ${ }^{2}$ \\ ${ }^{1}$ Faculty of Teacher Training and Education, Mulawarman University, Samarinda, Indonesia \\ ${ }^{2}$ Postgraduate Program of State University of Makassar, Makassar, Indonesia \\ Correspondence: Istanti Hermagustiana, Faculty of Teacher Training and Education, Mulawarman University, \\ Samarinda, Indonesia. E-mail: istanti.ana81@gmail.com
}

Received: May 22, 2017 Accepted: June 12, 2017 Online Published: July 26, 2017

doi:10.5539/ijel.v7n5p34 URL: http://doi.org/10.5539/ijel.v7n5p34

\begin{abstract}
Teachers are highly influenced by their cognitions related to their ideas, to their views of the world, and to their values and conceptions of their environment. The study of teachers' cognitions forms a part of the process of understanding how teachers conceptualize their work (Hassankiadeh, 2012). Therefore, this study attempted to investigate the cognitions the Indonesian EFL teachers hold about vocabulary instruction along with analyzing reflected cognitions in their teaching practices in classroom context. This qualitative study used semi-structured interview and direct classroom observation to obtain the data from four Indonesian EFL teachers of senior high school. It was revealed that the teachers have well-developed cognitions about EFL vocabulary instruction. It is shown from their beliefs, understanding, and perceptions about the role of vocabulary, its importance in EFL teaching and learning including what words are taught and how words are taught. Moreover, some aspects of their cognitions about vocabulary teaching emerge to be in congruence with their vocabulary teaching practices although some inconsistencies have been identified as well.
\end{abstract}

Keywords: teacher cognition, vocabulary instruction, EFL vocabulary, teaching vocabulary

\section{Introduction}

\subsection{Background}

In recent years, a great number of attempts on teachers' cognition have been made with the aim of understanding the complications reinforcing the teachers' cognitions and their classroom practices (Baker, 2014). Teachers are highly influenced by their cognitions which are related to their ideas, to their views of the world, and to their values and conceptions of their environment. It is certainly not new that prospective teachers bring with themselves many cognitions about the nature of teaching and learning and that these cognitions interact with the content and pedagogy of their teaching procedures and influence what and how they teach. The study of teachers' cognitions forms a part of the process of understanding how teachers conceptualize their work (Hassankiadeh, 2012). In last two decades, teacher education research has made significant advances in studying teacher cognitions, and the connection between their cognitions and educational practice has already been well established (Borg, 2003). In short, how teachers have seen and experienced learning and teaching can be an important problem in learning/teaching field because it shall affect their cognitions and subsequent actions in teaching situations.

Despite their role as language components, grammar is more focused than vocabulary in the classroom practice, which can be seen from a number of earlier studies. EFL teachers' cognitions related to the teaching of grammar have been well studied (Borg, 2001; Borg \& Burns, 2008; Farrell \& Lim, 2005; Phipps \& Borg, 2009), EFL vocabulary teachers' cognition, however, has received considerably less attention. As a matter of fact, learning vocabulary or lexicon is one of the most important domains in the process of learning a language for the aim of communicating and should be considered as significant part of teaching and learning languages too. About its significance in learning a language it can be said that limited knowledge of English vocabulary may affect the performance of English language learners at school (Cummins, 1994). During the past decades, researchers have pointed to the importance of vocabulary acquisition for second language (L2) learners (Allen, 1983; Laufer, 1986; Nation, 1990; Richards, 1980). However, there has been little or no well-prepared research about how 
teachers' cognitions about vocabulary instruction influence their instructional practices, particularly in Indonesian context. In terms of research methodology, EFL teachers' cognition research pertaining to vocabulary so far has included relatively little classroom observation data collection.

\subsection{Research Questions}

Based on the background above, the researchers seek to investigate two major points as follows:

1) What cognitions do the EFL teachers hold about vocabulary instruction in their classrooms in Indonesia?

2) How are the EFL teachers' cognitions reflected into their teaching practices?

\subsection{Literature Review}

\subsubsection{Teacher's Cognition}

Even though there is not any clear cut distinction between abstract concepts of knowledge and beliefs because of their intertwined similarity of features and overlapping natures (Verloop, Van Driel, \& Meijer, 2001), an attempt has been made to provide a unified shelter for both concepts under the term of teacher cognition. Consequently, Borg (2003) uses the term "teacher cognition" to refer to "unobservable cognitive dimension of teaching — what teachers know, believe, and think" (p. 81). In clearer definition, Borg (2006) defines language teacher's cognition as "an often tacit, personally-held practical system of mental constructs held by teachers and which are dynamic - i.e., defined and refined on the basis of educational and professional experiences throughout teachers' lives" (p. 35). In other words, the major concern of teacher cognition, therefore, lies with teachers' mental lives. The perception of teacher cognition includes a variety of notions like teachers' knowledge, perceptions, beliefs, attitudes, theories, assumptions, conceptions, principals, thinking, and decision-making towards their actual performances and practices in a specific context (Borg, 2006).

Richards, Gallo \& Renandya (2001) have stated that beliefs were found to be far more influential than knowledge in determining how individuals organize and define tasks and problems, and were better predictors of how teachers behaved in the classroom than other factors. In addition, they argue that teachers' beliefs are derived from their prior experiences, school practices, educational theory, reading, their individual personalities, and a number of other sources (Richards, Gallo \& Renandya, 2001). Moreover, Rifkin (2000) explains that teachers' beliefs about the learning/teaching process are "of crucial importance to the success or failure of learners' efforts to master a foreign language" (p. 394). Furthermore, Richards (1998) sees teachers' belief systems as "the information, attitudes, values, expectations, theories, and assumptions about teaching and learning that teachers build up over time and bring with them to the classroom" (p. 66). In other words, teachers' beliefs generally "refer to teachers' pedagogical beliefs, or those beliefs of relevance to an individual's teaching" (Borg, 2001, p. 186), and they are acquired through what Lortie (1975) cited in Johnson (1994) called the "apprenticeship of observation", or the "vivid memories of 10,000 hours in classrooms that help new teachers determine what they want to be and do in teaching" (p. 160). As a result, teachers' beliefs are well formed by the time students receive training in the teacher education.

Based on Phipps \& Borg (2007), there are some aspects about the nature of teacher cognition and its relationship to what teachers do as follows:

a. Teachers' cognitions can be powerfully influenced by their own experience as learners;

b. These cognitions influence what and how teachers learn during teacher education;

c. They act as a filter through which teachers interpret new information and experience;

d. They may outweigh the effects of teacher education in influencing what teachers do in the classroom;

e. They can be deep-rooted and resistant to change;

f. They can exert a persistent long-term influence on teachers' instructional practices;

g. They are, at the same time, not always reflected in what teachers do in the classroom;

h. They interact bi-directionally with experience (i.e., beliefs influence practices but practices can also lead to changes in beliefs).

Based on the above generalizations, it can be argued that "when teachers enter professional development programs at either the pre-service or the in-service level, they bring with them an accumulation of experiences that manifest themselves in beliefs that tend to be quite stable and rather resistant to change" (Johnson, 1999, p. 30). Teachers' cognitions act as a filter through which new information is interpreted and influence the way teachers react and respond to what happens in the classroom. 


\subsubsection{Vocabulary Teaching Practice and research in Indonesia}

Since English is regarded as a foreign language in Indonesia, lack of exposure to English vocabulary turns out to be the reason why vocabulary acquisition is problematic. It is not surprising, therefore, that Indonesian EFL learners' lack of vocabulary knowledge are revealed by several studies. It was Quinn (1968) who was interested in finding out the number of English words the students mastered after six years of study in secondary school. He assessed the students by using a translation vocabulary test and discovered that the students knew fewer words than one thousand of the most frequent English words after six years of study.

In addition, Kweldju (1997) carried out a vocabulary-size study to 15 Indonesian student teachers of English Department. She found those future English teachers only knew 4664 word forms or 2800 word families, a vocabulary size still below the threshold level for reading academic texts. It can be concluded that ELT teachers have failed in offering sufficient word knowledge that is a precondition for effective language use.

In addition, Kweldju (1999) conducted a research on collocation mastery. A list of 25 items of collocations was distributed to sixty English Department students to determine whether they were familiar with these items and given five possible options: known, fairly known, little known, hardly known, and unknown. The results of the study showed that in general the students were able to supply only a few expected collocations, whereas most of the students were familiar with several collocations. These findings suggest that many Indonesian learners of English were not aware of collocations and, therefore, it is recommended that teachers and learners focus on collocations in the classroom and they should be deliberately learned.

Furthermore, Nurweni's (1997) study revealed that on average, the 324 subjects knew 987 of the 2000 most frequent words, and 239 of the 808 university words, making up 1226 words in total. It was concluded that the students' mastery of small number of words was likely to result from forgetting in which they forgot most of the words already exposed, thus did not acquire them well. The loss of so many words already exposed pertains to the need for increasing the number of word repetitions.

What's more, most Indonesian EFL teachers do not know how to measure their students' vocabulary knowledge, what words to teach and how to teach the words since they still believe in vocabulary myths and are not aware of recent research findings (Folse, 2004). Moreover, the teachers often complain that their students do not have enough vocabulary knowledge, and the students themselves often admit that they do not know many of the words in a text.

\subsubsection{Congruence and Incongruence between Teacher Cognition and Teaching Practice of Vocabulary}

A number of studies have attempted to examine the extent to which teachers' cognitions influence their classroom practices. Findings from the mainstream research collectively suggest that language teachers' instructional practices are affected by a wide range of interacting and often conflicting factors. Even though teachers' cognitions are known to be influential on their instructional practices, they do not always reflect teachers' stated beliefs, personal theories, and pedagogical principles.

In a study on the relationship between thirty ESL teachers' beliefs and practices during literacy instruction, Johnson (1992) identified three different methodological positions among these teachers: a skills-based approach, which views language as being composed of four discrete language skills; a rules-based approach, which views language as a process of creative manipulation of grammar rules; and a function-based approach, which focuses on the communicative ability in real-life contexts. The majority of the teachers in the study were found to hold beliefs which consistently reflected one of these approaches and perform their instructional practices conforming to the corresponding theoretical orientation.

Moreover, a study on teacher cognition was carried out by Niu \& Andrew (2012) who investigated L2 teachers' beliefs and practices about vocabulary pedagogy from a small culture perspective. This study was a qualitative study which employed semi-structures interviews, classroom observation and involved four EFL teachers in China. In the end, the study revealed two big themes with regard to teachers' beliefs about vocabulary teaching. Those themes entailed teachers' shared and discrepant beliefs. In terms of the consistency between teachers' beliefs and their pedagogical practices, it was shown that some beliefs were consistent with the teaching practices, while some others were not due to a number of factors, such as time constraint of classroom practice and China's classroom culture.

Additionally, Macalister (2012) conducted a mixed-method study which examined three groups of participants: (1) 60 Malaysian pre-service teachers whose teacher education programme consists of roughly equal time spent in Malaysia and New Zealand, (2) 16 Malaysia-based teacher educators, and (3) six New Zealand-based trainers. This study used a questionnaire and interview to gain data from the participants. It was revealed that the most 
obvious difference in terms of the role of vocabulary in language learning seen from the survey data was in views on the role of reading in learning new words. Simultaneously, the findings of this study suggest that although trainees clearly hold a range of beliefs about language learning, including the role of vocabulary, these tend not to be evident in their descriptions of teaching, such as no obvious understanding of how to direct attention to useful or important words nor how to facilitate the learning of new words.

In addition to teacher cognition about vocabulary teaching and learning, teacher cognition about grammar teaching obtained through the use of questionnaire was examined by Moini (2009). This study investigated differences in non-native EFL teachers' beliefs about grammar and teaching grammar. The differences were sought across teachers' work environment, private school versus state schools, degree, gender, and teaching experience. A sample of $130 \mathrm{EFL}$ teachers teaching at junior high school, high schools, and private language institutes were randomly selected. The sample consisted of EFL teachers with different degrees, teaching experience, and gender. A grammar belief questionnaire consisting of five main categories (25 items) was administered. The results showed significant differences between school teachers and institute language teachers in their cognition and practice. The observed differences were also significant for teachers with BA degree, MA degree and teaching experience. However, teachers' beliefs did not significantly differ in genders. All in all, the results showed that teachers' characteristics influenced some aspects of their cognition and teaching practices as related to grammar.

In the area of vocabulary instruction, Hedrick, Harmon, \& Linerode (2004) investigated the vocabulary beliefs and instructional practices of social studies teachers in intermediate and middle school grades as well as their use of teachers' manuals. It was found that there was discrepancy between what teachers believe about vocabulary learning and their actual instructional practices for supporting vocabulary in teaching social studies. While their reported beliefs appear to mirror what is currently accepted as effective vocabulary instruction, their reported practices reflect more traditional notions like those found in many social studies textbook manuals. The inconsistency between beliefs and practices in this study is differentially affected by grade level, economic status, or number of years of teacher experience.

Last, in Rahimi's (2014) study on teacher cognition and vocabulary teaching, it was found out that before teaching any word, all related psychological aspects of a single word should be taken into consideration. In addition, due to personalized nature of every teacher's cognition, all the variables related to cognition would be invaluable according to the contextual factors. In other words, teachers' decisions about teaching vocabulary are fully affected through a number of variables, such as learning experience and contextual factors.

\section{Method}

\subsection{Research Design}

This study focused on an exploratory investigation of teachers' cognitions and reflection of the implementation of vocabulary instruction in their cognition. Therefore, a qualitative data collection method was employed for this study.

\subsection{Participants}

Four EFL teachers of senior high school in East Kalimantan, Indonesia, voluntarily participated in this study. These four teachers were selected based on the following criteria: (1) They taught English to the students of grade XI. Grade XI teachers were chosen since the teachers of Grade XII were not allowed to take on such an intervention program as classroom observation due to the students' preparation for National Examination; (2) They used the most current curriculum, which is Kurikulum 2013 (K-13), for the lesson plans; (3) The selected teachers had, at least, 5-year experience as English teachers since it was expected that the teachers had held considerable cognitions about vocabulary instruction during pre- and in-service teaching programs ; (4) The teachers were those selected after some informal consultation with headmasters of the schools as well as their colleagues. From the abovementioned criteria, four EFL teachers were selected and subsequently named as T1, $\mathrm{T} 2, \mathrm{~T} 3$, and $\mathrm{T} 4$.

\subsection{Instrument}

The data were obtained through semi-structured interview and classroom observation. The questions of semi-structured interview were constructed by the researcher by considering the theoretical framework of teacher cognition. In addition, the researcher employed observation guide and field notes to record the data from observation. During the observation, the researcher acted as a non-participant observer sitting in the back of the classrooms. 


\subsection{Data Analysis}

Data were thematically analyzed and consequently categorized into a number of areas: teachers' beliefs about vocabulary role, teachers' knowledge about vocabulary teaching and learning, prior language learning experience, and some factors impeding the flow of classroom instruction.

\section{Results and Discussions}

\subsection{Analysis of Teacher Cognition about Vocabulary Instruction}

The results of data analysis showed that EFL teacher participants perceived considerable aspects of vocabulary instruction based on their background knowledge and teaching experience.

\section{Beliefs about Role of EFL Vocabulary}

The participants believed that vocabulary had a significant role in their EFL teaching practices. Based on the findings, the teacher participants saw the role of vocabulary from distinct standpoints. Most of the teachers who took into account that vocabulary played an essential part in language teaching and learning viewed it as a must-teach item in the classroom. One of the teachers asserted that the role of vocabulary was very important since vocabulary helped learners speak, write, or understand what someone spoke or wrote. In contrast, the only participant who considered it a merely motivating factor in language teaching and learning perceived it as a complement in classroom practice. The teacher clarified,

"I think it (vocabulary) doesn't have a great role in language \& teaching since it is only to motivate the students. I mean, motivate students here is like telling and showing them that by having large vocabulary, you will be able to speak English fluently, write in English, listen and read English texts well too. So, learning vocabulary is a motivation for them to achieve bigger goals as I said before".

The divergent perceptions on seeing vocabulary role result from the teachers' experiences in their classroom context. This finding showed that the way teachers saw and experienced learning or teaching process could be important in learning or teaching field because it would affect their beliefs and subsequent actions in teaching situations (Borg, 2003).

\section{Knowledge about vocabulary teaching and learning}

There were two dimensions revealed from the interview data concerning vocabulary teaching and learning in classroom context, what words were taught and how the words were taught. The participants exhibited quite similar views on these issues. Some differences, however, arose. Pertaining to words which were considered to be taught as the second salient theme, the teachers selected them based on the themes in the syllabus and the type of words, namely: word classes and word frequency. When the teachers were equipped with a particular textbook from the government, for example, they merely took the words available in the reading texts or in the exercises. The teacher stated,

"The government gives us textbooks and in that book there is also new vocabulary before and then we will discuss the words".

In addition, the teachers took into account the types of words to be taught which include word classes, such as nouns, verbs, adjectives, and adverbs. The teacher affirmed,

"When reading a text, all types of words are there, noun, verb, adverb, and adjective. So I need to teach them all and show them the differences between all of them. The function or position of each word...So it is very necessary".

In addition to the word types, the teachers maintained that word frequency was also one of the considerations when selecting words to be inserted in their teaching practice. Two teachers were of the same opinion that the words taught should be those which the students rarely heard or saw. It was clarified,

"Most of the words given or taught to my students are new words which I think they never hear before. So what I give in the beginning of the lesson, new words, the meanings are difficult, or the words are seldom used".

In brief, all participants were in agreement about the vocabulary selected for instructional practices as long as the words are part of the teaching materials based on the teaching syllabus. Additionally, they asserted that all parts of speech were supposed to be included in the instruction and more unfamiliar words, considered low frequency words, should be focused on more than high frequency words.

The second dimension which was revealed from the data was the way the words were taught in the classroom. These four teachers agreed that vocabulary was best integrated into English skills in order for their students to 
get more understanding of word meanings. Since vocabulary was not taught exclusively in her classroom, it was inferred that vocabulary integration was the best choice for the students. In the teacher's view,

"We (teachers) are suggested to teach the material integrated, so when we teach speaking, reading, listening and writing, when we teach the four skills, we usually connect the materials with vocabulary mastery. For example, in reading. In teaching reading, there are many texts, there are many words and we discuss them. Also for listening, speaking and writing”.

Based on the data analysis, vocabulary could be incorporated into all of the skills comprising listening, speaking, reading, and writing. However, as a receptive skill, reading was considered the best skill vocabulary was integrated into. One of the teachers declared,

"Yes, teaching word meanings through reading texts is the strategy that I often do the most in the classroom because it is effective to increase students' vocabulary".

Moreover, reading was the best medium for vocabulary incorporation due to the fact that this skill was regarded as the primary skill in the National Examination. Two of the participants emphasized that vocabulary turned out to be very vital in reading texts as it helped the students improve their reading comprehension. The teacher stated,

"Yes, very important. Because with the limited vocabulary they have, I'm sure they can't face especially for the $3 \mathrm{rd}$ grade for the national examination because $80 \%$ of the test is reading texts".

Furthermore, another participant was convinced that vocabulary could help the students comprehend reading passages and answer the comprehension questions. She stated,

"And I have conclusion about how to improve reading, how to improve their scores in the final examination, it is vocabulary".

Prior Language Learning Experience

Teacher's previous learning experience is one of the important elements which explains the existence of teacher cognition in the classroom. By seeing the prior experience the teachers had in their past learning, this might influence their teaching practice in the classroom. Almost all teachers in this study agreed that the language learning strategies they did as English learners in the past did not significantly contribute to the language teaching strategies they employed in the classroom. One of the most frequently employed strategies the participants did was word memorization. However, this learning strategy was not believed to be good to improve their vocabulary knowledge.

One of the teachers believed that memorization or rote learning was not effective in acquiring new English words. As a learner, that strategy did not effectively help her develop her vocabulary. She affirmed,

"My teacher asked me to memorize ten words every meeting. Yeah, I remembered the first ten words but then I forgot them after memorizing ten other words in the second meeting".

Therefore, she claimed that memorization needed to be followed by the practice of using the word in context as she asserted,

"The best way to learn new vocabulary is to recall or memorize the new words along with their meanings, and then use them in spoke or written".

In addition, another participant agreed that memorization was the least effective in vocabulary retention. She claimed,

"I think I was required to recall some new words when I was in high school. After that, we, all of the students in the classroom, were asked to memorize them in front of our English teacher and after that activity, those words were not used anymore, so we easily forgot all of the words".

This became an important experience for her and also for her students in learning English vocabulary. Therefore, she frequently reminded the students of using the new words they had just learned in spoken or written context. She explained,

"I kept telling my students, even though you can memorize 10 words a day but you don't use them in your speaking or writing, you will forget them for sure. So, once you remember those words, apply them in your conversation or writing".

The observations from the two teachers showed that there was no memorization strategy used in their teaching practice. Instead, they applied more various teaching strategies, such as word elicitation through pictures or 
acquiring word meaning with synonyms, which entailed more students' active cognition than rote learning. This was in line with the teachers' beliefs about the ineffectiveness of word memorization in foreign language word acquisition.

\section{Impeding Factors towards Vocabulary Instruction}

The last aspect analyzed from the data pertained to some contextual factors which could impede vocabulary instruction in the classroom. The data exhibited several factors which could obstruct vocabulary teaching and learning process when the teachers were not aware of dealing with these in their instructional practices. Those factors included teachers' weakness in pronunciation, students' vocabulary deficiency, time constraint, exam-based syllabus, and lack of vocabulary teaching resources.

\subsection{Analysis of the Reflection of Teacher Cognition in Vocabulary Teaching Practices}

Some of the teachers' cognitions are reflected through their instructional practices in the classrooms; whereas, some are not. This section will deeply elaborate both correspondence and discrepancy between teachers' cognitions and their vocabulary teaching practices.

Correspondence between EFL teachers' cognitions and their vocabulary instructional practices

Overall, the four EFL teachers' shared cognitions were found to be congruent with their pedagogical practices in four main aspects, namely: (1) the involvement of vocabulary instruction in the teachers' pedagogical practices, (2) the incorporation of vocabulary teaching into the teaching of four skills of English through a number of vocabulary instructional strategies to diminish some barriers in students' language performance due to lack of vocabulary knowledge, (3) the teaching of all types of parts of speech in vocabulary instruction, and (4) the use of visual support to enhance students' vocabulary knowledge.

Despite the teachers' acknowledgement of the importance of vocabulary to support other English skills, their teaching preference style on implicit vocabulary instruction was reported in their interview results. Therefore, most of vocabulary teaching strategies they applied in the classroom were unplanned. This was consistent with their responses in the interview session that vocabulary was not the focus of their lessons in the classrooms, but when it happened to appear in their teaching process, they would not disregard it anyway.

Moreover, the congruence between cognition and practice was shown by one of the teacher participants who reported her weakness on English pronunciation. This self-perceived weakness was believed to restrain her from providing pronunciation practice to the students. Her instructional practice confirmed this. It showed that this lack of vocabulary knowledge in terms of word pronunciation had a negative impact on the teacher's performance in the classroom. This is aligned with some previous studies which have empirically proven this phenomenon (Gilakjani \& Ahmadi, 2011; Gilakjani \& Sabouri, 2016; MacDonald, 2002).

In addition, the technologically visual support (i.e., Power point (Ppt)) utilized by the EFL teacher participants looked very simple. The teachers' technological knowledge seemed to be limited on the use of Ppt as the supporting technological device used in their teaching practice. From the interview responses, the participants perceived Ppt as the regular technology-based teaching media in their classrooms. However, their responses revealed that some limitation on the use of Ppt fundamentally appeared. The limitation was shown due to the fact that, apart from the lesson using a video, the EFL teachers merely deployed Ppt which focused on simple pictures or written explanation with no movement or sounds on the slides during the observation. This is aligned with Asan (2003) who discovered that many teachers lacked a functional computer literacy foundation upon which to build new technology and skills, such as lack of knowledge and skills about using computers and insufficient training opportunities.

Most of the shared teaching strategies reported in the interviews were seen in the EFL teachers' pedagogical practices. One of the most frequently used vocabulary teaching strategies reported by the participants was direct translation from L1 to L2 or vice versa. The use of this strategy was congruent with the teachers' instructional practice in which direct translation was the most frequently selected strategy to infer word meanings. From the observation findings, all of the teachers employed translation strategy for all lessons they taught in each observed classroom practice. Another correspondence between teachers' cognition and teaching practice was the use of indirect pronunciation check strategy. It was the strategy used to provide feedback to the students' mispronunciation without telling them the mispronounced word directly; instead, the students were required to foster their awareness toward the mispronounced word. This reported strategy was found in the teachers' interview as the common strategy they applied, particularly in students' speaking performance. This interview results were confirmed in the pedagogical practices where some of the teachers implemented this strategy. However, the effectiveness of this strategy cannot be scrutinized further in this study. The next strategy that was 
congruent between what the teachers thought and did in the classroom was the use of pictures as visual support to enhance students' vocabulary knowledge. The teachers mostly used pictures to begin a lesson in order to elicit some information about what the students have already known previously pertaining to the lesson. Moreover, they shared similar views on the students' vocabulary enhancement through this strategy. Last, one of the most popular vocabulary teaching strategies in the EFL classroom in the use of context. Context covers both written and spoken contexts. In other words, the students not only derive a word meaning from written context, such as a reading text, but also from spoken context through teachers' verbal explanation. This strategy was frequently observed when the EFL teachers put a word into some context by which the students could guess its meaning.

Discrepancy between EFL teachers' cognitions and their vocabulary instructional practices

The discrepancy between EFL teachers' cognition and their instructional practices was shown from their perceptions towards the role of EFL vocabulary. Vocabulary instruction mainly took place in several conditions as shown by the observation data, such as when the students had problem understanding a word meaning or when they mispronounced a word in reading aloud or speaking performance. The findings from the interview showed that most of the EFL teacher participants took into account the essential role of vocabulary in their classroom practices. However, most of vocabulary teaching strategies occurring during the classroom observations were carried out without being planned. In other words, the teachers applied some particular strategies mainly when there were some lexical problems going on in the classrooms.

In contrast, one of the EFL teachers argued that vocabulary was only a supporting element in learning a language so that she did not focus much on vocabulary in the classroom, which means that the students learned new words indirectly while they were involved in learning English skills, such as speaking and writing. However, her lesson plans showed the opposite result. In one of the lesson plans, vocabulary was the focus of her teaching, particularly in a reading lesson. In addition, her instructional practices exhibited that she was concerned about vocabulary instruction where a huge number of vocabulary teaching strategies were employed in her teaching practice.

Another discrepancy between EFL teacher's cognition and the teaching practice pertains to the teacher's past learning experience. One of the teachers affirmed that word memorization was not effective to enhance students' vocabulary, based on her prior language learning experience. It means that her personal language learning experiences made her think that word memorization should be avoided. However, based on the observation data, she employed a number of memory strategies, such as word class analysis, pronunciation practice through drilling words, phrases, or sentences, word part analysis, direct translation, and synonym/antonym, to present vocabulary knowledge to her students. This result was aligned with Hassankiadeh (2013).

In addition, the EFL teachers' self perceptions on student-centered approach as regards the new curriculum (K13), which has been an ideal approach to be used in the classroom, contradicted their vocabulary teaching in which the initiation of vocabulary instruction primarily came from the teachers. Moreover, the teachers' reliance on textbooks in the classroom confirmed that teacher-centered instruction had been the implemented approach without the teachers' being aware of it. These findings echoed some previous studies on the use of textbooks in the classroom practice (Chien \& Young, 2006). Chien \& Young (2006) found out that the EFL teachers perceived textbooks as a tool for saving time and enhancing their teaching practice in spite of incomprehensive content and insufficient varied supports the textbooks offered.

Additionally, most of the EFL teacher participants perceived time constraint in their instructional practices as a barrier so that vocabulary teaching was frequently excluded. However, the data from the document show a little contradiction. Some vocabulary instruction was clearly stated in the lesson plan. Furthermore, it could also be seen from the observation data in which there were a huge number of vocabulary instructional strategies performed by the teacher participants in their classrooms. In other words, the teachers could freely employ a large number of strategies to teach vocabulary even though they were not prepared beforehand. However, practicing taught vocabulary was the issue which needs to be solved. Faraj (2015) maintains that spending more time on introducing the vocabulary instead of practicing it makes a gap between learning the word theoretically and practically.

Last, an inconsistency between a reported vocabulary teaching strategy in the interview and the use of the strategy during observations also occurred in this study. Vocabulary game was reported by more than one teacher; however, only one teacher applied this strategy to increase students' vocabulary knowledge before the teacher began the main lesson. The teachers who did not employ this strategy in their teaching practices assumed that time was the main barrier to carry it out. In other words, due to time limitation in the classroom, it was difficult for the teachers to reflect this strategy into their pedagogical practices. 


\section{Pedagogical Implications on EFL Teaching and Learning}

The first implication concerns how to integrate the aspect of vocabulary teaching within Indonesian EFL teacher education. It appears that Indonesian EFL teacher educators need to improve curriculum design options for EFL teacher education programs, highlighting the role of vocabulary in EFL learning and teaching. As the participants reported, vocabulary occupied a significant position in both EFL learning and teaching. This is consistent with other researchers' findings (Knight, 1994; Schmitt, 2000). Despite this evidence, Indonesian EFL teacher education programs do not provide solemn attention to vocabulary teaching practice. Therefore, it seems to be essential that Indonesian EFL teacher education programs should revise and expand curriculum design in this area to meet EFL teachers' needs. For instance, a TEFL (Teaching English as a Foreign Language) course may provide teacher candidates with practical suggestions on how to teach vocabulary along with introducing them to general teaching methodologies. Various vocabulary teaching techniques, as identified in this study, may also be introduced in this course. Moreover, a Vocabulary course should be provided as a compulsory course in this current curriculum used by the formal institutions.

The second implication goes to the EFL teacher educators who need to assist teacher candidates in developing teaching proficiency in the area of vocabulary instruction. It is necessary that EFL teachers be equipped with technological knowledge. Teachers' superficial knowledge on the use of technology for teaching was seen from their observed teaching practice where they merely applied very simple technology, such as Power point presentation, in delivering lessons. As a consequence, some training on the use of advanced technology for teachers should be taken into account by the teacher educators, the schools, and even the policy makers. These classroom challenges are aligned with Asan (2003) and Buabeng-Andoh (2012) who found out that teachers' lack of technological competence which involves lack of hardware, lack of knowledge and skills about using computers, lack of training or insufficient training opportunities, lack of teachers' confidence and crowded classrooms were determined as the most important problems faced by the teachers.

Third, the results of the study reported have implications for the teaching and learning of productive vocabulary knowledge for secondary school students in Indonesia. English teaching in secondary schools is used to being characterized by grammar and translation. Based on the findings, the EFL teacher participants concentrated more on students' receptive vocabulary development rather than to their productive vocabulary development. To make it balance, productive vocabulary knowledge should be integrated in the English curriculum by the development of communicative skills and the ability to exchange information effectively through both spoken and written channels. When reading a text, listening to a dialogue, or discussing a topic, students may incidentally learn some words or phrases. But the vocabulary is not learned in depth. In other words, students may acquire, through communicative tasks, a large number of words that they are able to recognize but could not use productively. In order to improve students' vocabulary knowledge in terms of both receptive and productive abilities, it is very important to combine learning vocabulary incidentally through communicative activities with explicit vocabulary learning. By explicitly learning different aspects of words (such as their meanings, forms, and use) and being exposed to these words in other areas of their course work, students will gradually be able to use them receptively and productively. Teachers may also include some vocabulary enhancement activities in language classes. For example, retelling stories, problem solving and information transfer activities are all very useful for students to learn to use words productively.

The last implication pertains to the nature of Indonesian school and national examination which focuses more on word meaning rather than the other vocabulary knowledge aspects, such as word form and word use. This is reflected through the content of the selected textbook which gives attention to the meanings of new words in a text or individual sentences. Based on the findings of this study, the used textbook taught to high school students does not have ample contexts for teaching vocabulary. Additionally, few sufficient sections are provided for students to practice vocabulary. This finding is in congruence with the findings of Jahangard (2007), Riazi \& Mosalanejad (2011), and Riazi \& Aryashokouh (2007) who suggest an immediate reformation with respect to the textbooks at high school level. Therefore, it is suitable and essentially needed for Indonesian EFL teaching programs to give a request to textbook designers to make required modifications or changes based on empirical research to remove this problem. Of course, teachers' cognitions and personal implications would definitely be constructive, if their theories are gathered through a comprehensive survey and contributed to the modifications. In addition, Indonesian EFL teaching programs also need to allocate more time to English course in high school as this is proven to be one of the major concerns of the participants. Based on the findings in this study, Indonesian EFL teaching programs additionally need to make a pleasing balance between the textbook objectives and the nature of final examinations they expect to be taken. 


\section{Conclusion}

This present research expands studies of L2 teachers' cognitions by investigating EFL teachers' cognitions of vocabulary instruction in Indonesia, particularly in Samarinda, East Kalimantan. It focuses on four areas, namely: teachers' beliefs about vocabulary role, teachers' knowledge about vocabulary teaching and learning, prior language learning experience, and some factors impeding the flow of classroom instruction. In addition, the study revealed some correspondence and discrepancy between teachers' cognitions and their vocabulary instructional practices. These results imply that a large amount of work needs to be carried out by the whole elements of education, such as teachers, students, schools, and even government, in order that the ideal picture of classroom instructional practices, particularly in teaching EFL vocabulary, can be attained.

Considering that the current study is the first of its type focusing on the relationship between teachers' cognitions and practices in English language teaching in Indonesian context, this study may contribute to the field of SLA. However, it is important to reiterate that there are some limitations of this study. First, the investigation of each EFL teacher participants was not carried out in one semester teaching-term due to the requests from the participants. Second, all research participants were female teachers and were incidentally selected for this study. Therefore, the involvement of male teachers might provide new insights for picturing teachers' cognitions about vocabulary instruction or other language areas in Indonesian classrooms. Third, students' perspectives on vocabulary instruction in the classroom have not been explored in this study since the success of English Language Teaching (ELT) is believed to begin by understanding teachers' cognitions before dealing more comprehensively with the students. Consequently, it would be beneficial for future researchers to consider scrutinizing students' cognition about English Language Learning (ELL).

\section{Acknowledgments}

Special gratitude goes to the Indonesian Ministry of Education of Culture that granted the author scholarship for the accomplishment of the study. The author would also like to express her thanks to Desy Rusmawaty, M. A. from Mulawarman University, Indonesia, for her suggestions and feedback for the article draft improvement.

\section{References}

Allen, V. F. (1983). Techniques in teaching vocabulary. Oxford: Oxford University Press.

Asan, A. (2003). Computer Technology Awareness by Elementary School Teachers: A Case Study from Turkey. Journal of Information Technology Education, 2, 153-164. Retrieved from http://jite.org/documents/Vol2/v2p153-164-109.pdf

Baker, A. (2014). Exploring teachers' knowledge of second language pronunciation techniques: teacher cognitions, observed classroom practices, and student perceptions. TESOL Quarterly, 0(0), 1-28. http://dx.doi.org/10.1002/tesq.99

Borg, S. (2001). Self-perception and practice in teaching grammar. ELT Journal, 55(1), 21-29. http://dx.doi.org/10.1093/elt/55.1.21

Borg, S. (2003). Teacher cognition in grammar teaching: A literature review. Language Awareness, 12(3), 96-108. http://dx.doi.org/10.1080/09658410308667069

Borg, S. (2006). Teacher cognition and language education: Research and practice. London: Continuum.

Borg, S., \& Burns, A. (2008). Integrating grammar in adult TESOL classrooms. Applied Linguistics, 29(3), 456-482. http://dx.doi.org/10.1093/applin/amn020

Buabeng-Andoh, C. (2012). Factors influencing teachers' adoption and integration of information and communication technology into teaching: A review of the literature. International Journal of Education and Development using Information and Communication Technology, 8(1), 136-155. Retrieved from http://files.eric.ed.gov/fulltext/EJ1084227.pdf

Chien, C. Y., \& Young, T. K. (2007). Are "textbooks" a barrier for teacher autonomy? A case study from a Hong Kong primary school. Education and Society, 25(2), 87-102. http://dx.doi.org/10.7459/es/25.2.06

Cummins, J. (1994). The acquisition of English as a second language. In K. Spangenberg-Urbschat \& R. Pritchard (Eds.), Kids come in all languages: Reading instruction for ESL students (pp. 36-62). Newark, DE: International Reading Association.

Faraj, A. K. A. (2015). Effective Strategies for Turning Receptive Vocabulary into Productive Vocabulary in EFL Context. Journal of Education and Practice, 6(27), 10-20. Retrieved from http://files.eric.ed.gov/fulltext/EJ1077387.pdf 
Farrell, T. S. C., \& Lim, P. C. P. (2005). Conceptions of grammar teaching: A case study of teachers' beliefs and classroom practices. TESL-EJ, 9(2). Retrieved from http://files.eric.ed.gov/fulltext/EJ1065837.pdf

Folse, K. S. (2004). Myths about teaching and learning second language vocabulary: What recent research says. TESL Reporter, 37(2), 1-13. $\quad$ Retrieved from http://www.vocablearning.com/WhyVocablearning/Folse-2004-MythsAboutTeachingAndLearningSecondL anguageVocabulary.pdf

Gilakjani, A. P., \& Ahmadi, M. R. (2011). Why is pronunciation so difficult to learn?. English Language Teaching, 4(3), 74-83. https://doi.org/10.5539/elt.v4n3p74

Gilakjani, A. P., \& Sabouri, N. B. (2016). Why is English pronunciation ignored by EFL teachers in their classes?. International Journal of English Linguistics, 6(6), 195-208. http://dx.doi.org/10.5539/ijel.v6n6p195

Hassankiadeh, M. A. G. (2012). Function-based vs. meaning-based beliefs in teaching vocabulary. Bellaterra Journal of Teaching \& Learning language \& Literature, 5(4), 20-41. Retrieved from http://www.raco.cat/index.php/Bellaterra/article/view/290222

Hassankiadeh, M. A. G. (2013). Different beliefs and teaching vocabulary: Memory-based vs. function-based beliefs. International Journal of Language and Linguistics, 1(1), 11-19. http://dx.doi.org/10.11648/j.ijll.s.20130101.13

Hedrick, W. B., Harmon, J. M., \& Linerode, P. M. (2004). Teachers' beliefs and practices of vocabulary instruction with social studies textbooks in grades 4-8. Reading Horizons, 45(2), 103-125. Retrieved from $\mathrm{http}: / /$ scholarworks.wmich.edu/cgi/viewcontent.cgi?article=1162\&context=reading_horizons

Jahangard, A. (2007). Evaluation of EFL materials taught at Iranian public high schools. The Asian EFL Journal Quarterly, 9(2), 130-150. Retrieved from http://www.asian-efl-journal.com/1062/quarterly-journal/2007/06/evaluation-of-efl-materials-taught-at-irani an-public-high-schools/\#squelch-taas-tab-content-0-3

Johnson, K. E. (1992). The relationship between teachers' beliefs and practices during literacy instruction for non-native speakers of English. Journal of Reading Behavior, 24(1), 83-108. http://dx.doi.org/10.1080/10862969209547763

Johnson, K. E. (1994). The emerging beliefs and instructional practices of preservice English as a second language $\begin{array}{lllll}\text { teachers. Teaching and Teacher } & \text { 4ducation, }\end{array}$ http://dx.doi.org/10.1016/0742-051X(94)90024-8

Johnson, K. E. (1999). Understanding language teaching: Reasoning in action. Boston: Heinle and Heinle Publishing Company.

Knight, S. (1994). Dictionary use while reading: The effects on comprehension and vocabulary acquisition for students of different verbal abilities. The Modern Language Journal, 78(3), 285-299. http://dx.doi.org/10.1111/j.1540-4781.1994.tb02043.x

Kweldju, S. (1997). English department students'vocabulary size and the development of a model of extensive reading with individualized vocabulary learning. Singapore: SEAMEO Regional Language Centre.

Kweldju, S. (1999). English department students collocation abilities. TEFLIN Journal, 10(1), 48-62. http://dx.doi.org/10.15639/teflinjournal.v10i1/48-62

Laufer, B. (1986). Possible changes in attitude towards vocabulary acquisition research. International Review of Applied Linguistics in Language Teaching, 24, 69-75. Retrieved from https://www.researchgate.net/publication/259820087_Possible_changes_in_attitude_toward_vocabulary_ac quisition_research

Macalister, J. (2012). Pre-service teacher cognition and vocabulary teaching. RELC Journal, 43(1), 99-111. http://dx.doi.org/10.1177/0033688212439312

MacDonald, S. (2002). Pronunciation-views and practices of reluctant teachers. Prospect, 17(3), 3-18. Retrieved

from http://www.ameprc.mq.edu.au/docs/prospect_journal/volume_17_no_3/17_3_1_MacDonald.pdf

Moini, M. R. (2009). The impact of EFL teachers' cognition on teaching foreign language grammar. Pazhuhesh-e Zabanha-ye Khareji, 49, 141-164. Retrieved from https://jor.ut.ac.ir/pdf_27678_a8071223c679b0b19b43b72cf84a2d5b.html 
Nation, I. S. P. (1990). Teaching and learning vocabulary. Boston, MA: Heinle \& Heinle.

Niu, R., \& Andrews, S. (2012). Commonalities and discrepancies in L2 teachers' beliefs and practices about vocabulary pedagogy: A small culture perspective. TESOL Journal, 6, 134-154. Retrieved from https://www.researchgate.net/profile/Stephen_Andrews3/publication/265266822_Commonalities_and_Disc repancies_in_L2_Teachers'_Beliefs_and_Practices_about_Vocabulary_Pedagogy_A_Small_Culture_Perspe ctive/links/54 ef01 $000 \mathrm{cf} 25238 \mathrm{f} 93 \mathrm{~b} 7 \overline{2} \mathrm{cb} . \mathrm{pdf}$

Nurweni, A. (1997). How many words do senior high school students acquire per week. TEFLIN Journal, 8(1), 103-115. Retrieved from https://lib.atmajaya.ac.id/default.aspx?tabID=61\&src=a\&id=250029

Phipps, S., \& Borg, S. (2007). Exploring the relationship between teachers' beliefs and their classroom practice. The Teacher Trainer, 21(3), 17-19.

Phipps, S., \& Borg, S. (2009). Exploring tensions between teachers' grammar teaching beliefs and practices. System, 37(3), 380-390. http://dx.doi.org/10.1016/j.system.2009.03.002

Quinn, G. (1968). The English Vocabulary of some Indonesian University Entrants: A Report on a Survey Conducted at the Christian University and Teacher College of Satya Wacana. Salatiga, Indonesia: IKIP Kristen Satya Wacana.

Rahimi, S. (2014). Teacher cognition vis-à-vis vocabulary teaching. Theory and Practice in Language Studies, 4(3), 652-660. https://doi.org/10.4304/tpls.4.3.652-660

Riazi, A. M., \& Aryashokouh, A. (2007). Lexis in English textbooks in Iran: Analysis of exercises and proposals for consciousness-raising activities. Pacific Association of Applied Linguists, 11, 17-34. Retrieved from $\mathrm{http} / / / \mathrm{s} 3$.amazonaws.com/academia.edu.documents/38685582/Lexis_in_English_textbooks_in_Iran_Riazi_ 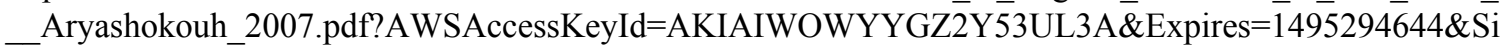 gnature $=$ ccz54Ici5iv7rFy5pONjxADpIbU\%3D\&response-content-disposition=inline $\% 3 \mathrm{~B} \% 20$ filename $\% 3$ DLexis_in_English_textbooks_in_Iran.pdf

Riazi, A. M., \& Mosalanejad, N. (2010). Evaluation of learning objectives in Iranian high-school and pre-University English textbooks using Bloom's taxonomy. TESL-EJ, 13(4). Retrieved from http://www.tesl-ej.org/wordpress/issues/volume13/ej52/ej52a5/

Richards, J. C. (1980). The role of vocabulary teaching. In K. Croft (Ed.), Readings in English as a second language: For teachers and teacher trainers (2nd ed., pp. 424-438). Cambridge, MA: Winthrop.

Richards, J. C. (1998). Beyond training: Perspectives on language teacher education. New York: Cambridge University Press.

Richards, J. C., Gallo, P. B., \& Renandya, W. A. (2001). Exploring teachers' beliefs and the processes of change. $\begin{array}{lllll}P A C & \text { Journal, } & \text { Retrieved } & \text { from }\end{array}$ http://aaboori.mshdiau.ac.ir/FavouriteSubjects/exploring-teacher-change.pdf

Rifkin, B. (2000). Revisiting beliefs about foreign language learning. Foreign Language Annals, 33(4), 394-408. http://dx.doi.org/10.1111/j.1944-9720.2000.tb00621.x

Schmitt, N. (2000). Vocabulary in language teaching. Cambridge: Cambridge University Press.

Verloop, N., Van Driel, J., \& Meijer, P. C. (2001). Teacher knowledge and the knowledge base of teaching. International Journal of Educational Research, 35(5), 441-461. http://dx.doi.org/10.1016/s0883-0355(02)00003-4

\section{Copyrights}

Copyright for this article is retained by the author(s), with first publication rights granted to the journal.

This is an open-access article distributed under the terms and conditions of the Creative Commons Attribution license (http://creativecommons.org/licenses/by/4.0/). 